\title{
Vocal fold medialization with autologous fat
}

\author{
Silvia Zapata ${ }^{1}$, Melissa Castillo-Bustamante ${ }^{1 *}$, Marisa Casiraghi ${ }^{1}$, Patricia Farías ${ }^{1}$, Luis Gesú ${ }^{2}$, Juan Di Bittonto ${ }^{2}$, María Andrea Ricardo $^{1}$ and \\ Francisco Gabriel Errea ${ }^{2}$ \\ ${ }^{1}$ Departmentof Otorhinolaryngology, Hospital Británico of Buenos Aires \\ ${ }^{2}$ Department of Plastic Surgery, Hospital Británico of Buenos Aires
}

\begin{abstract}
The autologous fat injection has been described as a method for treatment of dysphonia associated to presbylarynges, vocal fold paralysis, vocal cord scar, postcordectomy type I-III and bowing. Its purpose is to augment the volume of vocal fold allowing improvement of phonatory parameters and voice perception through tools as video laringostroboscopy, Voice Handicap Index,GRBAS scale and maximum phonation time. We report two cases of autologous injection in patients with sulcus vergeture and post type $\mathrm{V}$ cordectomy with 2 months follow-up evaluation results.
\end{abstract}

\section{Introduction}

The use of autologous fat grafts has been described in some laryngeal pathologies as unilateral vocal foldparalysis and scars, presbylarynges, sulcus, and after cordectomies due to laryngeal cancer [1,2]. Autologous fat grafts are notrejected and provide optimal vibratory properties for the vocal folds and are relatively easy to manipulate. Abdominal fat, has been described as one of the autologous graft used; it is obtained and harvested during the same operation where the laryngoscopic injection is perfomed. This proceeding consists on inject the substance to add bulk to the vocal fold(s) and affords one potential for permanent fat retention and long-termeffect $[2,3]$. Few studies, have evaluated the short- and long-term effects of abdominal autologous injection on voice outcome. These case series aim to describe dos cases of patients undergoing autologous fat injection on their vocal folds, one with previous Sulcus Vocalis and other after a type V cordectomy with $\mathrm{CO} 2$ laser $[3,4]$, their follow-up and speech therapy changes valorated with video laringostroboscopy, Voice Handicap Index Score, GRBAS scale and maximum phonation time.

\section{Method}

Case number 1: Male patient, 57 years old, non-voice professional, no smoking consulted for dysphonia after 1 year. On the video laringostroboscopic evaluation a bilateral sulcus vergeture has been observed. His initial perceptual evaluation was perfomed with the score of GRBAS of Hirano [5] where each item was qualified from 0 to 3 ( $0=$ normal, $1=$ mild, $2=$ moderate, $3=$ severe): Grade was qualified on 2 , roughness 2 breathiness 2 . A voice evaluation was perfomed on November 2017 maximum phonatory time was 8.5 seconds, the Voice Handicap Index-10 (VHI-10) purposed by Jacobson [6] modified by Rosen [7] was obtained on 16 that means moderate perception of dysphonia.

Case number 2: Female patient, 63 years old, non-voice profesional, consulted on 2016 for dysphonia at the Otolaryngology department. A pre-malignant lesion that occupied the total surface of the left vocal fold, anterior commissure and anterior sector of right vocal fold on the vido laringostroboscopic evaluation was found. A Type - V cordectomy wasperfomed with $\mathrm{Co} 2$ laser. Serial follow-up visits were perfomed.
Dysphonia persisted after surgery and two surgeries executed for intracordal sinequia and fibrin on anterior commissure on april and May of 2017. After these follow-up appointments, dysphonia was qualified with the GRBAS scale with Grade qualified on 2, Roughness 2 , breathiness 2 ; a voice evaluation was perfomed where maximum phonatory time was 8.2 seconds and VHI-10 result were 14 (moderate).

For both patients after voice evaluation and video laringostroboscopic findings, an autologous fat injection was purposed for dysphonia management.

\section{Surgical technique}

An initial periumbilical injection between fatty and dermal planes with Klein solution (50 ml of lidocaine $1 \%, 1 \mathrm{cc}$ of epinephrine 1:1.000, on each $1.000 \mathrm{cc}$ of saline solution). After 15 minutes, $20 \mathrm{ml}$ of fat were aspired from the periumbilical region with a liposuction-like technique with a liposuction cannula using a 10-cc disposable autostatic Luerlock syringe (Figure 1). The fat was put on 2 syringes and stand in one separated place of the surgical table, the inner piston was pulled out to create a vacuum and a decantation and emulsification processes were perfomed. The harvested Fat continued with a homogenization process and after, was put on three $1 \mathrm{cc}$ syringes for vocal fold application.

The autologous fat application was perfomed with a transoral approach under video-microscopic control, a needle was put on the paraglottic space of vocal fold and at least one injection site was adopted, an augementation of the entire vocal cord was seen during the proceeding. (Figure 2)

For patient of case number 1, a transoral approach was perfomed and $1 \mathrm{ml}$ of fat was placed in each vocal fold after paraglottic access (Figure 3). On patient of case number 2, the same approach was made

Correspondence to: Melissa Castillo Bustamante, Department of Otorhinolaryngology, Buenos Aires British Hospital, Buenos Aires, Argentina, Tel: +54 91143096400 - 2622; E-mail: melissacastillobustamante@gmail.com

Received: January 18, 2018; Accepted: January 30, 2018; Published: February 02,2018 


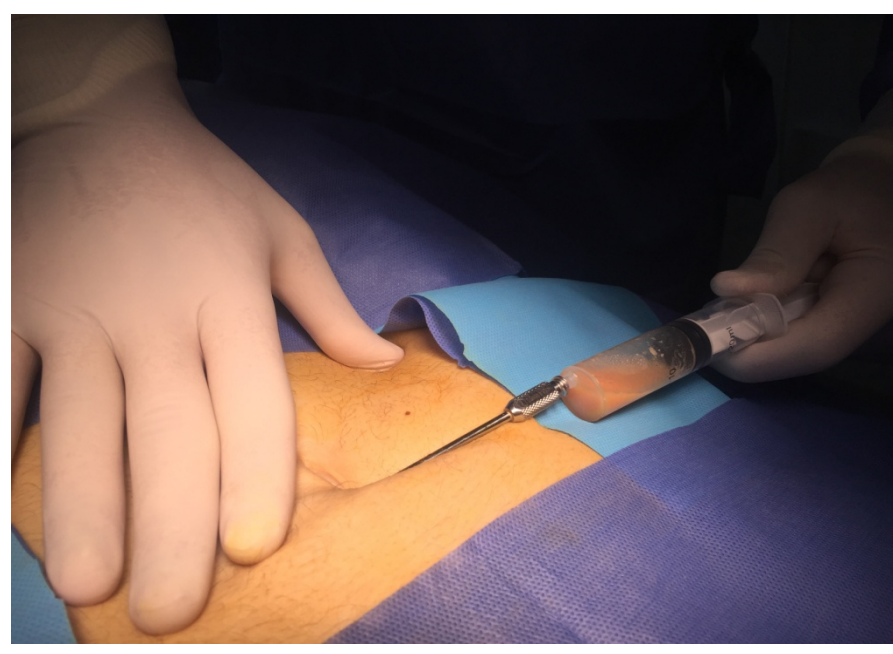

Figure 1. Extraction of autologous fat injection on periumbilical area.

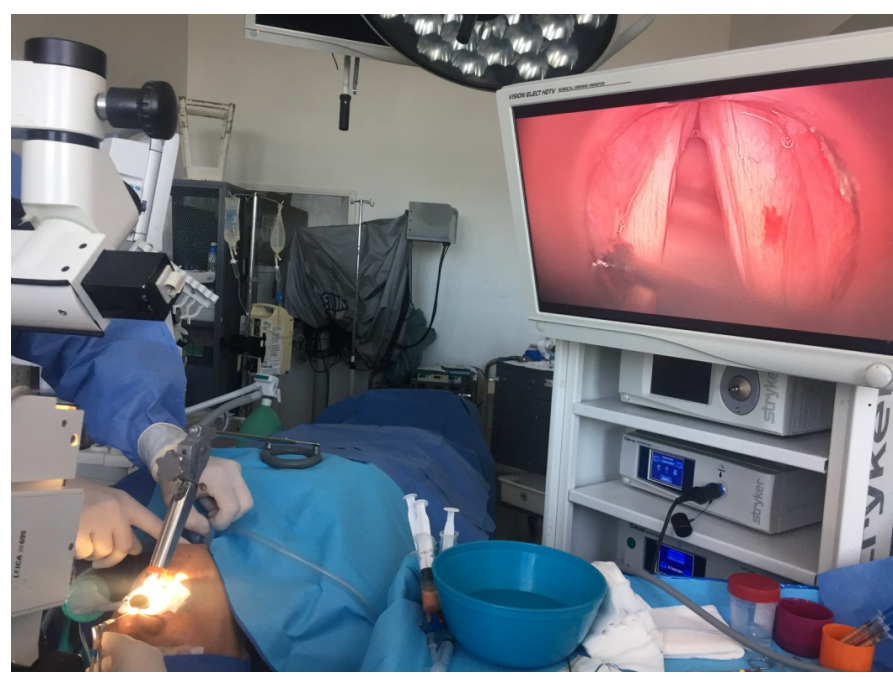

Figure 2. Fat injection on the vocal fold under video microscopic assistance.
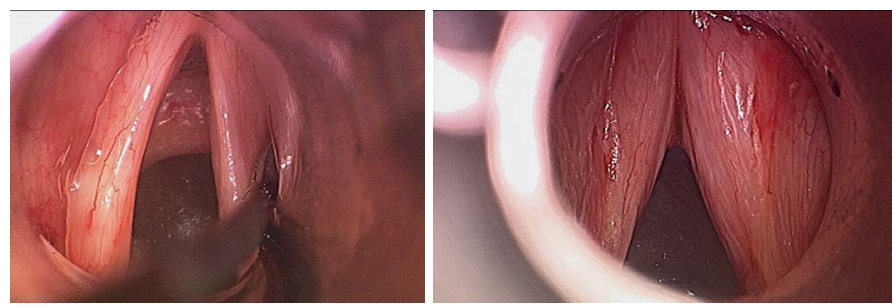

Figure 3. Pre and post placement of autologous fat injection.

but on the left vocal fold, two injections were perfomed and on the right vocal fold one point was injected.

\section{Follow up}

Case 1: Patient was valorated two months after surgery on January 2018, The GRBAS scale was punctuated as Grade 1, Roughness 1 and breathiness 1; his maximum phonatory time was 11.2 seconds and the VHI-10 was obtained on 8 (mild). (Figure 3 )

Case 2: Patient consulted after two months of surgery on December 2017, The GRBAS scale was punctuated as Grade 2, Roughness 2 and breathiness 1; her maximum phonatory time was 13.2 seconds and the VHI-10 was obtained on 10 (mild).

\section{Discussion}

These case reports described two patients with dysphonia and different larynx injuries: bilateral sulcus vergeture and Type Vcordectomy after laryngeal cancer. One with dysphonia associated to his laryngeal disorder and the order with persistent dysphonia after three surgeries who seeks for voice improvement. For both patients there were found major vocal fold gap on the video laringostroboscopy evaluation, after autologous fat injection, a relevant close of mentioned gaps were described. Voice assessment for patients, showed initial moderate scores on the Voice Handicap index and on GRBAS qualification showed moderate perception of voice. Both patients two months after autologous fat injection described dysphonia perception improvement mainly on breathiness qualification of GRBAS scale. These findings are associated to major glottic close obtained after autologus fat injections due to a volume augment on vocal folds that allowed less air leak and prolonged maximum phonatory time.

The improvement of maximum phonatory time has been described for authors as Hartl $[8,9]$ on patients with autologous fat injection mainy after 6 weeks of follow-up $[9,10]$, with mean difference of 6 seconds, our patients obtained a difference of 3 and 5 seconds respectively after two months follow-up. Even though some studies have described their improvement on VHI and maximum phonatory time [11] on 6 weeks follow up mainly in patients treated for vocal fold paralysis, vocal scars, post cordectomy type I- III and bowing $[3,12]$, we described similar results in two months after surgery, obtaining for injuries as sulcus and post cordectomy type $\mathrm{v}$ similar values as reported in less time. We continue following our patients after 6 and 1-year fat injections, further descriptions about follow up will be done on the future.

Autologous fat injection is useful in sulcus and post-cordectomy treatment, being a viable procedure with objective improvement of the phonatory parameters, voice and dysponia perception.

\section{References}

1. Bolzoni A, Piazza C, Redaelli L, Cattaneo A, Cocco D, et al. (2007) Phono surgery after endoscopic cordectomies. Primary intracordal autologous fat injection after transmuscular resection: preliminary results. Eur Arch Otorhinolaryngol 264: 11791184. [Crossref]

2. Kruschewsky Lde S, de Mello-Filho FV, dos Santos AC, Rosen CA (2007) Autologous fat graft absorption in unilateral paralyzed canine vocal folds. Laryngoscope 117: 96100. [Crossref]

3. Benninger MS, Hanick AL, Nowacki AS (2016) Augmentation Autologous Adipose Injections in the Larynx. Ann Otol Rhinol Laryngol 125: 25-30. [Crossref]

4. Pinto JA, da Silva Freitas ML, Carpes AF, Zimath P, Marquis V, et al. (2007) Autologous grafts for treatment of vocal sulcus and atrophy. Otolaryngol Head Neck Surg 137: 785791. [Crossref]

5. Hirano M (1981) Clinical Examination of Voice. Springer, New York [Crossref]

6. Jacobson BH, JonsonA, Grywalski C (1997) The Voice Handicap Index (VHI): development and validation. Am J Speech Lang Pathol 6: 66-70.

7. Rosen CA, Lee AS, Osborne J, Zullo T, Murry T (2004) Development and validation of the voice handicap index-10. Laryngoscope 114: 1549-1556. [Crossref]

8. Hartl DM, Hans S, Vaissiere J, Brasnu DF (2005) Laryngeal aerodynamics after vocal fold augmentation with autologous fat vs thyroplasty in the same patient ArchOtolaryngol Head Neck Surg 131: 696-700. [Crossref]

9. Hartl DM, Hans S, Vaissière J, Brasnu DF (2003) Objective acoustic and aerodynamic measuresofbreathinessinparalyticdysphonia. Eur Arch Otorhinolaryngol 260: 175-182. [Crossref]

10. Shaw GY, Szewczyk MA, Searle J, Woodroof J (1997) Autologous fat injection into the vocal folds: technical considerations and long-term follow-up. Laryngoscope 107: 177-186. 
11. Fang T-J, Li H-Y, Gliklich RE, Chen YH, Wang PC, et al. (2010) Outcomes of fat injection laryngoplasty in unilateral vocal cord paralysis. Arch Otolaryngol Head Neck Surg 136: 457-462. [Crossref]
12. McCulloch TM, Andrews BT, Hoffman HT, Graham SM, Karnell MP, et al. (2002) Long-term follow-up of fat injection laryngoplasty for unilateral vocal cord paralysis. Laryngoscope 112: 1235-1238. [Crossref]

Copyright: $(02018$ Zapata S.This is an open-access article distributed under the terms of the Creative Commons Attribution License, which permits unrestricted use, distribution, and reproduction in any medium, provided the original author and source are credited. 